\title{
OPTICAL COHERENCE TOMOGRAPHY OF ADIPOSE TISSUE AT PHOTODYNAMIC/ PHOTOTHERMAL TREATMENT IN VITRO
}

\author{
IRINA YU. YANINA* and NATALIA A. TRUNINA \\ Physics Department, Saratov State University, Saratov \\ 83 Astrakhanskay str., 410012, Russian Federation, Russia \\ *irina-yanina@list.ru \\ VALERY V. TUCHIN \\ Physics Department, Saratov State University, Saratov, \\ 83 Astrakhanskay str., 410012, Russian Federation, Russia \\ Laboratory of Laser Diagnostics of Technical and Living \\ Systems of Precise Mechanics and Control Institute \\ of the Russian Academy of Sciences \\ 24 Rabochaya Str., Saratov, 410028, Russian Federation, Russia \\ Optoelectronics and Measurement Techniques Laboratory \\ University of Oulu \\ P. O. Box 4500, FIN-90014 Oulu, Finland
}

Received 14 November 2012

Accepted 30 December 2012

Published 5 March 2013

\begin{abstract}
Temporal changes in structure and refractive-index distribution of adipose tissue at photodynamic/photothermal treatment were studied with OCT in vitro. Ethanol-water solutions of indocyanine green (ICG) and brilliant green (BG) were used for fat tissue staining. CW laser diode $(808 \mathrm{~nm})$ and LED light source (442 and $597 \mathrm{~nm}$ ) were used for irradiation of stained tissue slices. The data received supporting the hypothesis that photodynamic/photothermal treatment, induces fat cell lipolysis during a certain period of time after light exposure.
\end{abstract}

Keywords: Optical coherence tomography; adipose tissue; effective refractive index; photodynamic/photothermal treatment.

\section{Introduction}

One of the important problems of medicine and cosmetology is to find pathways of not harmful action on fat cells with the purpose of maintenance of their controllable lipolysis or destruction. Recently, we have shown ${ }^{1,2}$ that if the adipose tissue, stained with brilliant green (BG) or indocyanine green (ICG), is exposed to radiation of an

This is an Open Access article published by World Scientific Publishing Company. It is distributed under the terms of the Creative Commons Attribution 3.0 (CC-BY) License. Further distribution of this work is permitted, provided the original work is properly cited. 
appropriate light source (LED lamp or NIR laser), the photodynamic and/or selective photothermal effects can give rise to controllable lipolysis of fat cells and their gradual destruction following the scenario of apoptosis and/or necrosis. In this paper, the possibility of non-invasive optical coherence tomography (OCT) monitoring of lipolysis as a result of photodynamic and/or selective photothermal treatment is demonstrated.

OCT provides three-dimensional imaging within optical scattering media (e.g., biological tissues) with micrometer resolution. ${ }^{3}$ The clinical use of OCT for visualization of morphological changes following photodynamic treatment (PDT) has been described earlier in ophthalmological applications. ${ }^{4-6}$

Refractive index is an important optical parameter of biological tissues. The OCT technique provides a high-accuracy measurement of tissue and blood index of refraction. ${ }^{7-9}$ For tissues that are typically inhomogeneous media, an effective refractive index can be introduced and used as an integral diagnostic parameter of the tissue condition.

The aim of the present work is to study the temporal variations of effective refractive index of the adipose tissue under its photodynamic/ photothermal treatment using two types of dyes in combination with visible/NIR radiation of diode lamp and laser sources.

\section{Model and Hypothesis}

BG and ICG are used to enhance the efficiency of light-tissue interaction in visible and infrared regions. ${ }^{10-12}$ ICG may also induce photodynamic/ photothermal ${ }^{1,2,13-18}$ and phototoxic ${ }^{19}$ effects. Relatively narrow absorption peaks of these dyes allow efficient and selective laser destruction of tissues, but a due caution is necessary, because the interaction with organic molecules of a tissue may shift the dye absorption peaks by $10-20 \mathrm{~nm} \cdot{ }^{16-18}$

The next step of the interaction between the dye and the cell is controlled by visible and NIR light exposure. The biological response of the photosensitized cell to light exposure can enlarge the damaged areas in the cell membrane and cause their subsequent transformation into actual pores. The latter can act as gateways for free fat acids (FFAs) leakage outside the cell, because the molecular size of FFAs does not exceed $1-2 \mathrm{~nm}$ in diameter. ${ }^{20}$

Cell lipolysis can be observed as optical clearing of photodynamically/photothermally modified fat tissue samples. ${ }^{20}$ Due to light-induced cell membrane porosity, the intracellular content of the cell (FFAs) percolates through the arising temporal pores into the interstitial space. As a consequence, the refractive index of the interstitial fluid (initially equal to $\left.n_{i}=1.36\right)^{21}$ becomes closer to the refractive index inside the adipocytes (fat refractive index, $\left.n_{a}=1.44\right)^{22}$ and due to the refractive index matching effect the optical medium becomes optically more homogeneous and more transparent to light. This is the possible mechanism of laser action on the photosensitized adipose tissue.

\section{Experimental Setup}

The experiments were carried out using a portable time-domain OCT system (THORLABS Spectral Radar OCT Systems) (see Fig. 1). In this system, the light source is a low-coherence broadband superluminescent diode (SLD) with the central wavelength $930 \pm 5 \mathrm{~nm}$ and the spectral bandwidth of $100 \mathrm{~nm}$. The coherence length that determines the axial resolution of the system is $6.5 \mu \mathrm{m}$ and transverse resolution is of $9 \mu \mathrm{m}$ on the air and the output power is $2 \mathrm{~mW}$. Transverse resolution of the OCT system was examined by a special microscopic scale. ${ }^{23}$ The light from the source is guided into a handheld Michelson interferometer probe, which splits the light into two separate optical paths. In our experiments, the probe was mounted in an adjustable holder. The reference arm path is terminated with a mirror, while the other path contains an imaging lens that focuses the light into the sample. This imaging lens is also used to collect the light that is backscattered or reflected from the sample. The light returning from both paths is recombined and directed into a spectrometer, which spatially separates the light to form the interference pattern that is then analyzed to yield the spectral OCT images. The whole OCT process was controlled by a personal computer. As a result of OCT imaging, one gets a 2D array of the digitized OCT signal with rows corresponding to lateral and columns to axial scanning (http://www.thorlabs.com/catalogpages/595.pdf).

\section{Materials and Methods}

\subsection{Tissue samples}

Fat tissue slices having the thickness $200-600 \mu \mathrm{m}$ were used in the in vitro experiments. Water-ethanol 


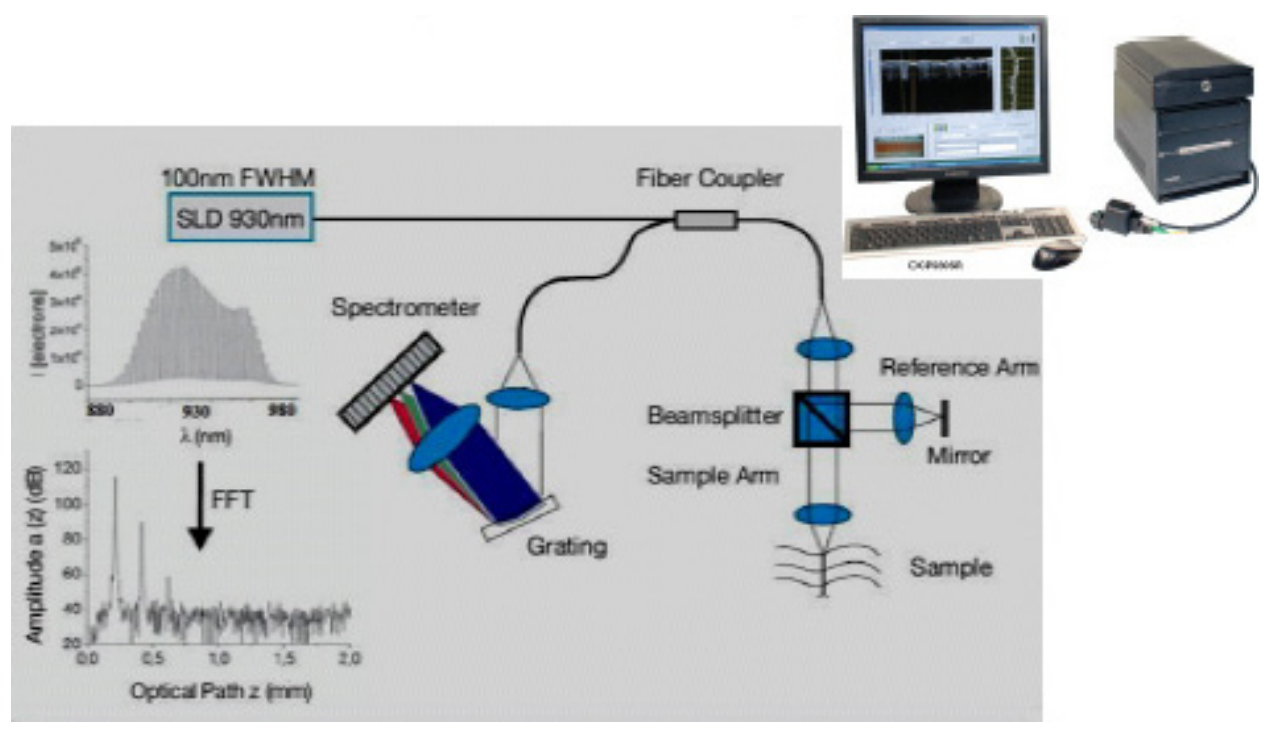

Fig. 1. Thorlabs spectral Radar OCT with a Handheld Probe (http://www.thorlabs.com/catalogpages/595.pdf).

solutions of ICG and BG with the concentration 1 and $6 \mathrm{mg} / \mathrm{mL}$, respectively, were used for fat tissue staining.

\subsection{Light sources}

The CW laser diode VD-VII DPSS $(808 \mathrm{~nm})$ and the dental diode irradiator Ultra Lume Led $5(442$ and $597 \mathrm{~nm}$ ) were used for irradiation of the samples. The exposure time was $5 \mathrm{~min}$ with the laser and $15 \mathrm{~min}$ with the diode lamp. All measurements were carried out at room temperature. The samples of adipose tissue were obtained as waist products of planned surgery.

The depth $z$ measured by OCT is actually the optical pathlength. Therefore, if the geometric thickness $l$ of the probed layer is known, the effective refractive index $n$ can be determined as ${ }^{8}$

$$
n=\frac{z}{l} \text {. }
$$

\section{Results and Discussion}

OCT imaging of the tissue samples stained with dyes was carried out before the irradiation, immediately after the irradiation and then repeatedly during a sufficiently long observation time period (up to $300 \mathrm{~min}$ ).

As an example Fig. 2 shows two OCT images of fat tissue slices, stained with BG, before (a) and after (b) the lamp irradiation during $15 \mathrm{~min}$. We used the diode lamp Ultra Lume Led 5 emitting at the wavelengths 442 and $597 \mathrm{~nm}$ with power density $75 \mathrm{~mW} / \mathrm{cm}^{2}$, respectively. The concentration of BG dissolved in the 2:3 ethanol-water solution was $6 \mathrm{mg} / \mathrm{mL}$. The thickness of the adipose tissue samples was measured using a micrometer. The measurement was repeated several times with subsequent averaging of the results. In the present case, this thickness was found to be $533 \pm 41 \mu \mathrm{m}$.

One can see obvious difference between Figs. 2(a) and 2(b). The light-induced change of the sample image is manifested as the appearance of a surface layer possessing no cell structure and looking as a uniform transparent medium presented by fat cell cytoplasm collected from the cells due to induced lipolysis. The optical thickness of this layer in Fig. 2(b) amounts to $60-100 \mu \mathrm{m}$, while the diameter of adipocytes is $60-70 \mu \mathrm{m}$ (in optical length units).

The same features were observed in ICG-stained fat tissue experiments (see Fig. 3).

The refractive index of the sample was calculated using Eq. (1). As already mentioned, the geometric thickness was measured using a micrometer. The optical pathlength was found from the OCT signal vs the depth (A-scan) as the difference between the depths of two peaks corresponding to the sample boundaries. To provide better determination of the boundaries, the A-scans were averaged over a certain lateral region $(2 \mathrm{~mm})$. This operation smooths out the stochastic noise and the random 


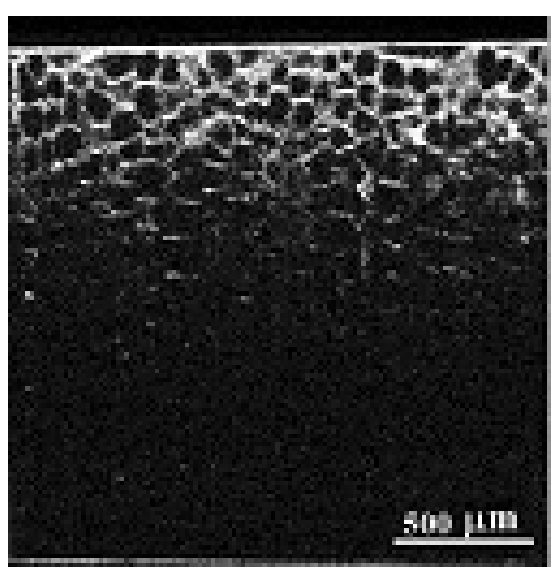

(a)

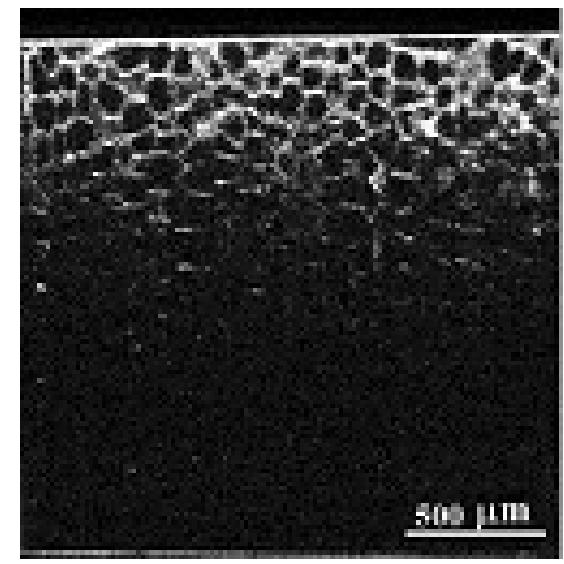

(b)

Fig. 2. OCT images of the BG-stained fat tissue before irradiation (a) and during 15 min after irradiation (b). The light source was dental diode irradiator Ultra Lume Led 5 (442 and $597 \mathrm{~nm}$ ). The concentration of BG in ethanol-water solution $(2: 3)$ was $6 \mathrm{mg} / \mathrm{mL}$.

cell structure of the tissue, while the peaks corresponding to the sample boundaries become more distinct. Examples of individual and averaged Ascans are presented in Fig. 4.

Since the OCT image resolves individual cells well enough, it is possible to study the effect of light exposure on the mean size of the cells. Table 1 presents the statistical analysis of cell image areas observed in Figs. 2(a), 2(b), 3(a) and 3(b). The average area of light-affected cells exceeds that of the intact cells by nearly $29 \%$ in the case of the BGstained fat tissue and $24 \%$ in the case of the ICGstained fat tissue, respectively.

The calculation of the refractive index reveals monotonic decrease of the refractive index with the increase of time period after irradiation (see Figs. 5 and 6). This may be due to a decrease of the relative refractive index of scatterers, indicating the immersion optical clearing. ${ }^{9}$

We interpret the observed changes in the OCT image as resulting from lipolysis and destruction of cells on the surface of the sample due to the photodynamic/photothermal effect. The intracellular fluid leaking from the cells fills the intercellular space, normally filled with interstitial fluid, thus causing the formation of cleared upper layer and optical clearing due to matching of the refractive indices of cells and intercellular medium.

In Ref. 24, chemically induced lipolytic activity was estimated by measuring the amount of glycerol released from cells into the surrounding medium. Moreover, by using time-lapse CARS imaging of a

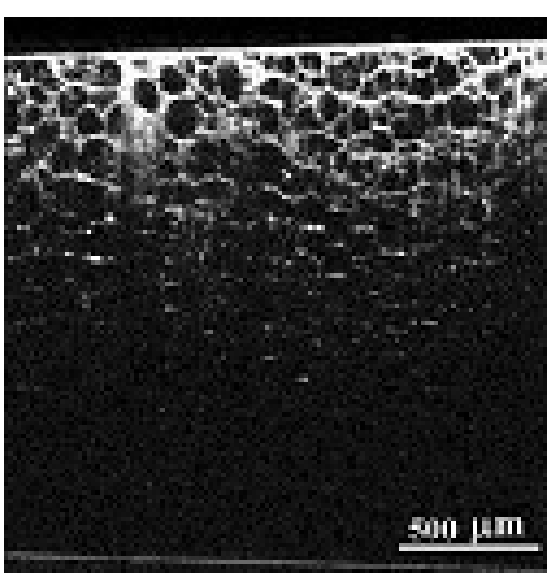

(a)

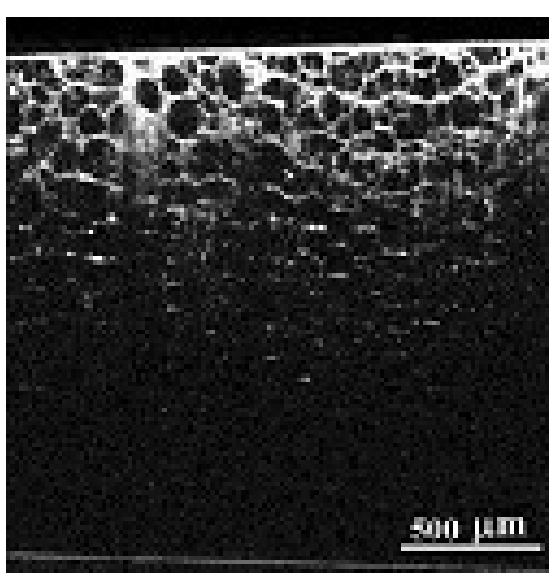

(b)

Fig. 3. OCT images of the ICG-stained fat tissue before irradiation (a) and during 5 min after irradiation (b). The light source was CW laser diode (VD-VII DPSS, $808 \mathrm{~nm}$ ). The concentration of ICG was $1 \mathrm{mg} / \mathrm{mL}$. 


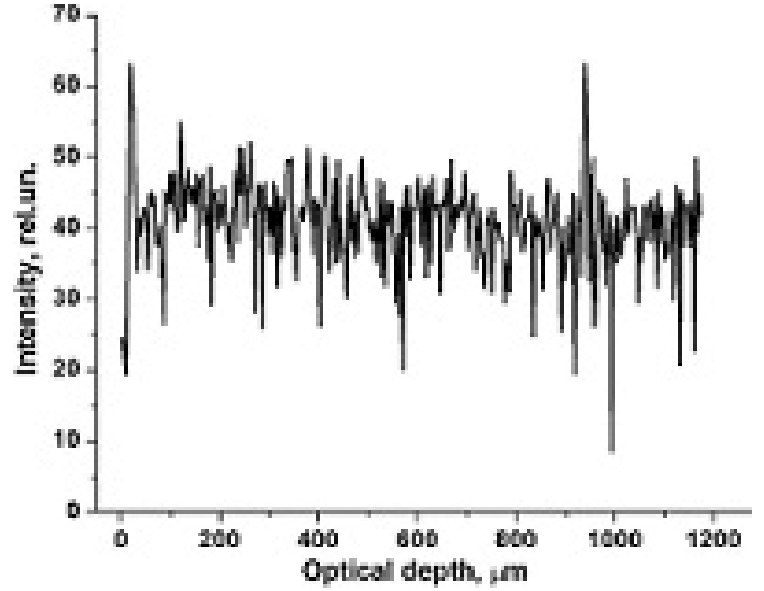

(a)

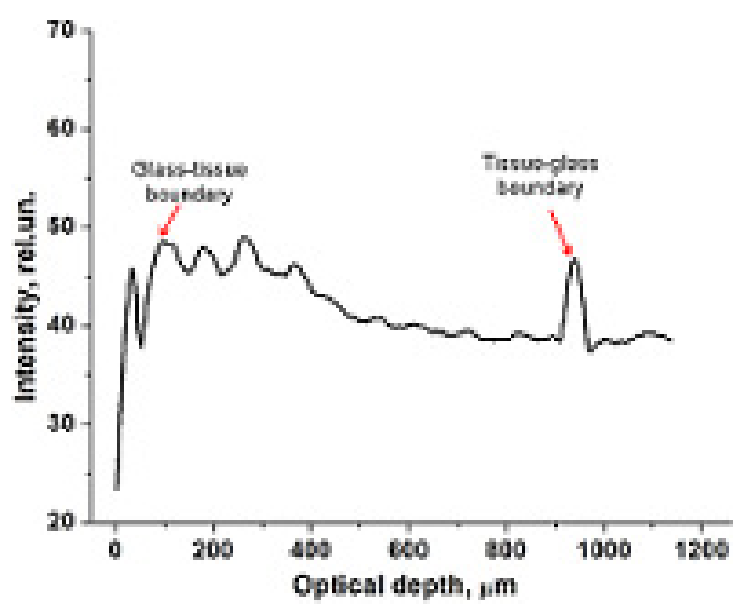

(b)

Fig. 4. Examples of A-scans: (a) individual; (b) averaged over the whole lateral interval seen in Fig. 2(b).

Table 1. Statistical analysis of light-induced changes in cell image area.

Mean area

(in optical length Standard The total number OCT image units), $\mu \mathrm{m}^{2} \quad$ deviation of cells observed

\begin{tabular}{llll}
\hline Fig. 2(a) & 4305 & 1173 & 59 \\
Fig. 2(b) & 6095 & 2028 & 43 \\
Fig. 3(a) & 4806 & 1771 & 91 \\
Fig. 3(b) & 6340 & 2006 & 89 \\
\hline
\end{tabular}

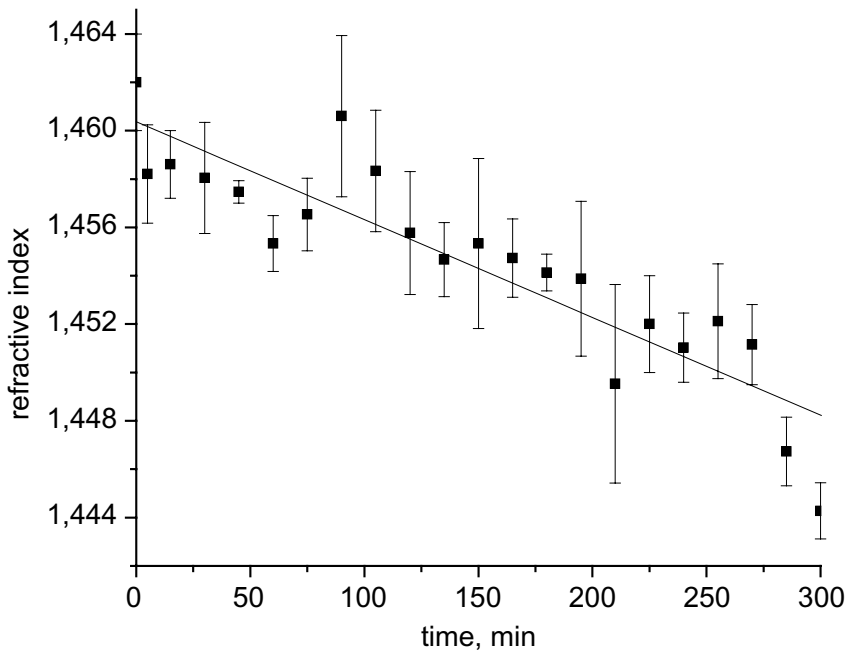

Fig. 5. The effective refractive index vs time elapsed after PDT for BG-stained fat tissue slice (diode lamp-irradiation during $15 \mathrm{~min}$ ). These are the statistical results for three independent measurements; solid line shows the linear fit by $n=1.460-4 \times 10^{-5} t$ (min). single live cell these authors were able to monitor the morphological changes of cell lipid droplets. They found that the micro-lipid droplets were formed gradually during the experiment, reaching diameters of about $1 \mu \mathrm{m}$ at $60 \mathrm{~min}$ post-stimulation. ${ }^{24}$ All these findings allows us to understand that similar processes may take place at lightinduced lipolysis.

Results of time-lapse OCT measuring of index of refraction of fat samples under light-induced lipolysis can be explained on the basis of time-dependent formation of two layers - one clear (cell release) and

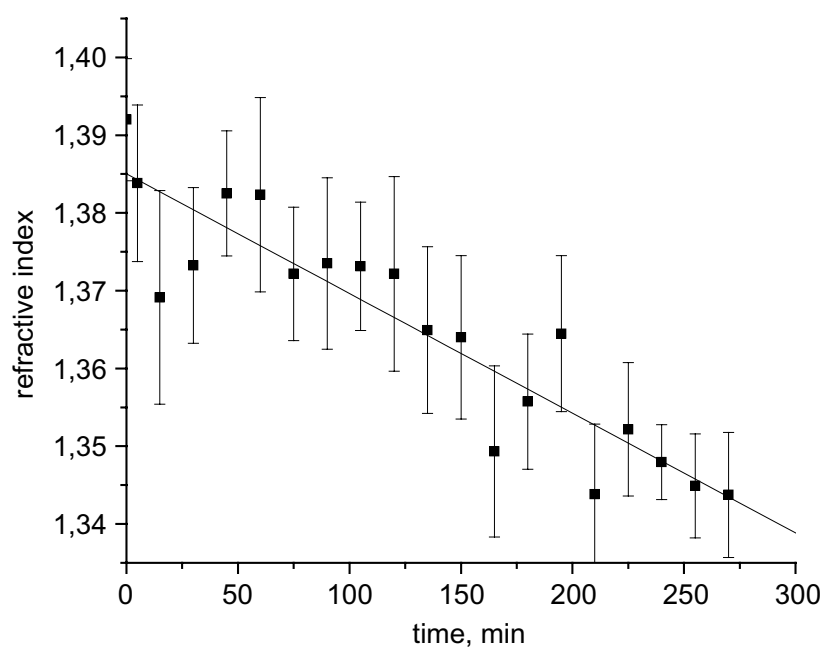

Fig. 6. The effective refractive index vs time elapsed after PDT for ICG-stained fat tissue slice (CW laser diode-irradiation during $5 \mathrm{~min}$ ). These are the statistical results for three independent measurements; solid line shows the linear fit by $n=1.386-1 \times 10^{-4} t(\mathrm{~min})$. 
another scattering (cells). The refractive index $m$ of the scattering medium can be expressed as $^{9}$

$$
m \equiv n_{0}+\Delta m=\bar{n}+\frac{\overline{n^{2}}-\bar{n}^{2}}{\bar{n}} Q(\lambda / l)
$$

where

$$
\bar{n}=n_{0}\left[1+\left(\frac{n}{n_{0}}-1\right) \frac{V_{s}}{V_{0}}\right],
$$

$V_{s}$ is the total volume of scattering particles, $V_{0}$ is the volume of the scattering medium, $\overline{n^{2}}$ is the mean squared value of refractive-index fluctuations, $Q(\lambda /$ $l$ ) refers to the form of scatters and their aggregation, and $l$ is the correlation length of randomly distributed refractive-index fluctuations. $Q=1.17$ in the limit of large correlation length, $l \gg \lambda$ (large particles). In the process of adipose tissue degradation, a twophase system of extracted fat cell cytoplasm [clear upper layer in Fig. 2(b)] and fat cells is formed. Each phase has its own thickness and refractive index. If we define the time-dependent thickness of the fat cell layer as $H(t)$ and the thickness of the upper clear cytoplasm layer as $[L-H(t)]$, then the average refractive index of the layer of thickness $L$, which contains two layers with different refractive indices, can be written in the form

$$
m_{T}=\frac{[L-H(t)]}{L} \bar{n}+\frac{H(t)}{L} m,
$$

where $m$ and $\bar{n}$ are defined by Eqs. (2) and (3). Because $m$ is always larger than $\bar{n}$ due to influence of scattering and the tissue degradation process leads to decrease of $H(t)$, the total refractive index must fall with time.

In the course of fat tissue degradation and producing more products of lipolysis outside the cells, the refractive-index matching conditions could be realized, that will lead to further decrease of scattering-dependent part of the index of refraction $m$. Therefore, both of the mechanisms of tissue degradation and refractive-index matching may explain the experimental decrease with time of the mean refractive index of a sample layer, which is caused by reduction of the scattering ability of the system.

\section{Conclusion}

Using the OCT imaging technique, we found that adipose tissue structure is modified and the integrative characteristic such as refractive index of tissue sample material, decreases with time after the treatment of dye-stained tissue with light. These data support the hypothesis that photodynamic/ photothermal treatment induces fat cell lipolysis during a certain period of time after the treatment.

It should also be pointed out that separate human fat cells are well seen by used OCT system due to its high longitudinal resolution within medium $\sim 6.5 / 1.4=4.6 \mu \mathrm{m}$. That allows for on-line cell size and shape monitoring in the whole tissue volume at any kind of impact on the cell functionality.

\section{Acknowledgments}

The authors would like to thank Dr. Genina E.A. for the help in evalution of transverse resolution of the OCT system. This study was supported by grant No 224014 PHOTONICS4LIFE of FP7-ICT2007-2, project No 1.4.09, RF Governmental contracts 11.519.11.2035, 14.B37.21.0728, and 14.B37. 21.0563; FiDiPro, TEKES Program (40111/11), Finland; SCOPES EC, Uzb/Switz/RF, Swiss NSF, IZ74ZO_137423/1; RF President's grant 1177.2012.2 "Scientific Schools."

\section{References}

1. V. V. Tuchin, I. Yu. Yanina, G. V. Simonenko, "Destructive fat tissue engineering using photodynamic and selective photothermal effects," Proc. SPIE 7179, 71790C-1-11 (2009).

2. I. Yu. Yanina, T. G. Orlova, V. V. Tuchin, G. B. Altshuler, "The morphology of apoptosis and necrosis of fat cells after photodynamic treatment at a constant temperature in vitro," Proc. SPIE 7887, 78870X-1-6 (2011).

3. D. Huang, E. A. Swanson, C. P. Lin, J. S. Schuman, W. G. Stinson, W. Chang, M. R. Hee, T. Flotte, K. Gregory, C. A. Puliafito et al., "Optical coherence tomography," Science 254(5035), 1178-1181 (1991).

4. A. García-Layana, A. Salinas-Alamán, M. J. Maldonado, C. Sainz-Gómez, A. Fernández-Hortelano, "Optical coherence tomography to monitor photodynamic therapy in pathological myopia," $B r . J$. Ophthalmol. 90, 555-558 (2006).

5. C. H. Park, B. T. Smith, M. Oh, S. Fekrat, "Optical coherence tomography following photodynamic therapy with verteporfin for subfoveal predominantly classic choroidal neovascularization," Ann. Ophthalmol. (Skokie) 38(2), 121-125 (2006). 
6. H. Ozdemir, S. Arf Karacorlu, M. Karacorlu, "Early optical coherence tomography changes after photodynamic therapy in patients with age-related macular degeneration," Am. J. Ophthalmol. 141(3), 574-576 (2006).

7. Zh. Meng, X. S. Yao, H. Yao, Y. Liang, T. Liu, Y. Li, G. Wang, S. Lan, "Measurement of the refractive index of human teeth by optical coherence tomography," J. Biomed. Opt. 14(3), 034010-1-4 (2009).

8. V. V. Tuchin (Ed.) Coherent-Domain Optical Methods: Biomedical Diagnostics, Environmental Monitoring and Material Science. Vol. 1, 2, 2nd Edition, Springer-Verlag, Berlin, Heidelberg, N.Y. (2012).

9. V. V. Tuchin, X. Xu, R. K. Wang, "Dynamic optical coherence tomography in optical clearing, sedimentation and aggregation study of immersed blood," Appl. Opt. 41(1), 258-271 (2002).

10. W. R. Chen, R. L. Adams, K. E. Bartels, R. E. Nordquist, "Chromophore-enhanced in vivo tumor cell destruction using an 808-nm diode laser," Cancer Lett. 94, 125-131 (1995).

11. W. R. Chen, R. L. Adams, S. Heaton, D. T. Dickey, K. E. Bartels, R. E. Nordquist, "Chromophoreenhanced laser-tumor tissue photothermal interaction using an 808-nm diode laser," Cancer Lett. 88, 15-19 (1995).

12. W. R. Chen, R. L. Adams, A. K. Higgins, K. E. Bartels, R. E. Nordquist, "Photothermal effects on murine mammary tumors using indocyanine green and an 808-nm diode laser: An in vivo efficacy study," Cancer Lett. 98(2), 169-173 (1996).

13. V. V. Tuchin, G. B. Altshuler, I. Yu. Yanina, V. I. Kochubey, G. V. Simonenko, "Fat tissue staining and photodynamic/photothermal effects," Proc. SPIE. Dynamics and Fluctuations in Biomedical Photonics VII, San Francisco, California, Vol. 7563, pp. 7563V1-7563V7, USA (2010).

14. V. A. Doubrovsky, I. Yu. Yanina, V. V. Tuchin, "Inhomogeneity of photo-induced fat cell lipolysis," Proc. SPIE 7999, 7999-79 (2011).

15. I. Yu. Yanina, V. A. Bochko, J. T. Alander, V. V. Tuchin, "Optical image analysis of fat cells for indocyanine green mediated near-infrared laser treatment," Laser Phys. Lett. 8(9), 684-690 (2011).

16. S. Fickweiler, R. M. Szeimies, W. Baumler, P. Steinbach, S. Karrer, A. E. Goetz, C. Abels, F. Hofstadter, M. Landthaler, "Indocyanine green: Intracellular uptake and phototherapeutic effects in vitro," J. Photochem. Photobiol. B Biol. 38, 178-183 (1997).

17. C. Abels, S. Fickweiler, P. Weiderer, W. Baumler, F. Hofstadter, M. Landthaler, R.-M. Szeimies, "Indocyanine green (ICG) and laser irradiation induce photooxidation," Arch. Dermatol. Res. 292, 404-411 (2000).

18. W. Baumler, C. Abels, S. Karrer, T. Weis, H. Messmann, M. Landthaler, R.-M. Szeimies, "Photooxidative killing of human colonic cancer cells using indocyanine green and infrared light," Br. J. Cancer 80(3/4), 360-363 (1999).

19. E. Engel, R. Schraml, T. Maisch, K. Kobuch, B. König, R.-M. Szeimies, J. Hillenkamp, W. Bäumler, R. Vasold, "Light-Induced decomposition of indocyanine green," Invest. Ophthalmol. Vis. Sci. 49, 1777-1783 (2008).

20. V. A. Dubrovskii, V. A. Dvorkin, I. Yu. Yanina, V. V. Tuchin, "Photoaction on cells of the human adipose tissue in vitro," Cell Tissue Biol. 5(5), $520-529$ (2011).

21. V. V. Tuchin, A. N. Bashkatov, E. A. Genina, Yu. P. Sinichkin, N. A. Lakodina, "In vivo study the dynamics of immersion clearing of human skin," Tech. Phys. Lett. 27(12), 10-14 (2001).

22. V. V. Tuchin, Optical Clearing of Tissues and Blood, SPIE Press Monograph Vol. PM154, SPIE Press, Bellingham, WA, USA (2006).

23. X. Wen, S. L. Jacques, V. V. Tuchin, D. Zhu, "Enhanced optical clearing of skin in vivo and optical coherence tomography in-depth imaging," J. Biomed. Opt. 17(6), 066022 (2012).

24. T. Yamaguchi, N. Omatsu, E. Morimoto, H. Nakashima, K. Ueno, T. Tanaka, K. Satouchi, F. Hirose, T. Osumi, "CGI-58 facilitates lipolysis on lipid droplets but is not involved in the vesiculation of lipid droplets caused by hormonal stimulation," J. Lipid Res. 48(5), 1078-1089 (2007). 